\title{
PENGEMBANGAN KEMAMPUAN TOUR GUIDE DESA WARNASARI KECAMATAN PENGALENGAN KABUPATEN BANDUNG
}

\author{
Alif Oktavia, Tine Ratna Poerwantika, Kunkunrat, \\ Rini Afriantari, \\ Jurusan Hubungan Internasional, Fakultas Ilmu Sosial dan Ilmu Politik, Universitas Pasundan \\ Jurusan Hubungan Internasional, Fakultas Ilmu Sosial dan Ilmu Politik, Universitas Pasundan \\ Jurusan Hubungan Internasional, Fakultas Ilmu Sosial dan Ilmu Politik, Universitas Pasundan \\ Jurusan Hubungan Internasional, Fakultas Ilmu Sosial dan Ilmu Politik, Universitas Pasundan \\ Email: alif.oktavian@unpas.ac.id, tine.ratnapoerwantika@unpas.ac.id, \\ kunkunrat@unpas.ac.id, rini.afriantari@unpas.ac.id
}

\begin{abstract}
ABSTRAK
Kawasan Wisata Desa Warnasari merupakan suatu tempat yang menawarkan daya tarik berupa pemandangan alam situ dan hamparan perkebunan. Kawasan Wisata Desa Warnasari diproyeksikan oleh Dinas Kebudayaan dan Pariwisata Kabupaten Bandung sebagai salah satu tujuan wisata unggulan di Bandung Selatan. Tujuan kegiatan ini adalah meningkatkan kemampuan Tour Guide Desa Warnasari Kecamatan Pengalengan Kabupaten Bandung Kegiatan dilaksanakan selama 3 bulan. Metode kegiatan menggunakan pelatihan. Sasaran kegiatan adalah Karang Taruna pengelola objek wisata Desa Warnasari berjumlah 30 orang. Hasil kegiatan ini membawa dampak positif dengan terlaksananya kegiatan pelatihan objek wisata sehingga terjadi peningkatan dalam hal pengelolaan objek wisata dan meningkatnya kemampuan Tour Guide Desa Warnasari Kecamatan Pengalengan Kabupaten Bandung.

\section{ABSTRAC}

The Warnasari Village Tourism Area is a place that offers the attraction of natural scenery and stretches of plantations. The Warnasari Village Tourism Area is projected by the Bandung Regency Culture and Tourism Office as one of the leading tourist destinations in South Bandung. The purpose of this activity is to improve the ability of the Tour Guide of Warnasari Village, Pengalengan District, Bandung Regency. Activities carried out for 3 months. Methods of using training. The target of the activity is Karang Taruna, the manager of the attractions of Warnasari Village, amounting to 30 people. The results of this activity have a positive impact with the implementation of tourist training activities so that there is an increase in the management of tourist objects and increased ability of the Tour Guide of Warnasari Village, Pengalengan District, Bandung Regency.
\end{abstract}

\section{A. PENDAHULUAN}

Kecamatan Pangalengan adalah salah satu kecamatan di Kabupaten Bandung yang terletak di sebelah selatan, yang terletak kurang lebih 29 kilometer dari kantor kabupaten. Dibatasi oleh Kecamatan Cimaung di sebelah utara, Kecamatan Talegong Kabupaten Garut di sebelah selatan, Kecamatan Pasirjambu di sebelah barat, Kecamatan Kertasari dan Kecamatan Pacet di sebelah timur. Kecamatan Pangalengan terbagi menjadi 13 desa yaitu Lamajang, Margaluyu, Margamekar, 
Margamukti, Margamulya, Pangalengan, Pulosari, Sukaluyu, Sukamanah, Tribaktimulya, Wanasuka, Warnasari, dan Banjarsari, status hukum seluruh desa adalah definitif yang didalamnya telah terbentuk lembaga-lembaga pemerintahan yang baik sesuai dengan aturan yang ada. Dilihat dari letak geografisnya Kecamatan Pangalengan terletak pada $107^{\circ} 29^{\prime}$ $107^{\circ} 39^{\prime}$ Bujur Timur dan $7^{\circ} 19^{\prime}-7^{\circ} 6^{\prime}$ Lintang Selatan. Sedangkan berdasarkan topografinya sebagian besar wilayah di Kecamatan Pangalengan merupakan pegunungan atau daerah perbukitan dengan ketinggian diatas permukaan laut bervariasi dari $984 \mathrm{~m}$ sampai $1.571 \mathrm{~m}$. Sebagian Besar desa terletak ditepian hutan, tetapi ada satu desa di luar kawasan hutan. Kecamatan Pangalengan juga dialiri salah satu Sungai Cisangkuy dan ada Situ Cileunca, keberadaan sungai dan Situ ini menguntungkan dari sektor pertanian dan Pariwisata dan sebagai bahan untuk Pembangkit Listrik Tenaga air juga di Kecamatan Pangalengan ada Pembangkit Listrik Tenaga Panas Bumi, namun bilacurah hujan cukup tinggi di daerah-daerah tertentu akan terjadi banjir bandang dan tanah longsor.

Luas wilayah berdasarkan beberapa kategori diantaranya luas lahan pertanian sawah (berpengairan teknis, berpengairan non teknis dan tidak berpengairan), luas lahan pertanian bukan sawah dan luas lahan non pertanian. Desa dengan luas lahan pertanian sawah terluas adalah Desa Lamajang dengan 836,42 Ha dan luas lahan sawah terkecil ada di Desa Pulosari dengan luas

Ha. Jika dilihat Kecamatan Pangalengan luas lahan pertanian bukan sawah cukup besar Seluas 24.171,46 Ha area bukan sawah terluas terletak di Desa Pulosari dengan 4.722,90 Ha dan luas areal bukan sawah terkecil terletak di Desa Tribaktimulya dengan 294,6 Ha dan luas area non pertanian terluas sama terletak di Desa Pulosari tercatat $391,85 \mathrm{Ha}$ serta terkecil tercatat ada di Desa Tribaktimulya seluas 77,00 Ha. Luas lahan sawah ada penurunan dari tahun sebelumnya disebabkan ada peralihan penggunaan status lahan menjadi lahan bukan sawah. Letak Kecamatan Pangalengan yang berada di dataran tinggi atau pegunungan membuat suhu udara di kecamatan ini cukup sejuk, yaitu berkisar antara $16^{\circ}$ celcius $-25^{\circ}$ celcius dan pada tahun 2015 curah hujan $1.996 \mathrm{~mm} /$ tahun dengan ratarata $5,47 \mathrm{~mm} /$ perhari, jumlah hari hujan terbanyak tercatat 22 hari terjadi di bulan Maret, hari hujan terkecil pada bulan juli tercatat 8 hari.

Pangalengan selain menjadi daerah di daerah Jawa Barat yang sangat popular selain sebagai produsen dan penghasil susu segar sapi terbaik di daerah Bandung juga dikenal sebagai daerah wisata alam Bandung yang masih alami dan sangat mempesona juga dengan suhu udara yang sangat dingin bias dirasakan pada malam hari.

Potensi pariwisata pangalengan yang merupakan daya tarik wisata antara lain :

1. Situ Cileunca.

2. Pemandian air panas Cibolang

3. Situ Cisanti

4. Situs Rumah Adat Cikondang

5. Kebon The Malabar

6. Curug Panganten

7. Sungai Palayangan

8. Gunung Malabar

9. Gunung Nini

Daerah Wisata diatas adalah sebagian dari destinasi pariwisata yang ada di wilayah Pangalengan selain daerah wisata Pangalengan merupakan salah satu kecamatan di Kabupaten Bandung yang merupakan daerah sentra pertanian. Sektor pertanian menyumbang terbesar dari total produk domestik regional 
bruto Kecamatan Pangalengan bahkan ke tingkat Kabupaten, penyumbang ketiga terbesar setelah sektor industri (tanpa migas), pertambangan dan penggalian (minyak dan gas bumi). Melihat potensi yang ada maka sektor pertanian merupakan sektor yang patut mendapat perhatian lebih, baik dari pihak pemerintah daerah maupun masyarakat pertanianitusendiri.

Beberapa jenis tanaman pangan yang diusahakan di Kecamatan Pangalengan, antara lain padi, jagung, ubi kayu, ubi jalar, kacang panjang dan kacang merah. Produksi dan luas tanaman pangan terbanyak adalah tanaman padi sawah sebanyak 6.267 ton, dengan luas panen 1.481 Ha sedangkan tertinggi kedua adalah jagung sebanyak 5.886 ton, luas panen 393 Ha. Hal ini mempengaruhi tingkat produktivitas tanaman padi menjadi 42,32 kw/Ha ditahun 2017 ada kenaikkan ditahun sebelumnya.

Padi dan palawija produksinya masih berada di peringkat bawah. Keadaan ini dapat dipahami karena luas areal untuk tanaman padi cukup kecil jika dibandingkan dengan luas areal yang ditanami tanaman holtikuktura yaitu seluas 2159,50 Ha untuk tanaman kentang dengan produktifitas 42.889 ton, tanaman kol 1.214,60 Ha produksi 30.634,00 ton, tanaman cabe 345,69 Ha produksi 4.094 ton, tanaman bawang merah 374,83 Ha produksi 20.358 ton, tanaman wortel 806,00 Ha produksi $18.520,80$ ton, tanaman tomat 665,85 Ha produksi 15.494 ton, tanaman labu siam 12,00 Ha produksi 55.650,50 ton, dan tanaman sawi 791,00 Ha produksi 18.054 ton sedangkan tanaman pangan dan holtikultura lainnya berkisar antara 1 hingga 56 Ha saja. Untuk semua tanaman di tahun 2017 mengalami penaikan dan penurunan di tahun sebelumnya disebabkan yang utama faktor cuaca yang tidak menentu.

Primadona di Kecamatan Pangalengan adalahTanaman holtikultura dibandingkan dengan tanaman pangan lainnya, tanaman holtikultura memiliki tanaman unggulan yaitu sepert kentang, kol, petsai/sawi, wortel, tomat, labu siam, bawang merah, cabe serta diikuti tanaman buah- buahan yaituh jeruk, alpukat dan pisang. Untuk Tanaman perkebunan seperti, teh dan kopi, strawberi yang juga usahakan di Kecamatan Pangalengan.

Peternakan menjadi unggulan di daerah ini. Berdasarkan jenis peternakan dibedakan atas ternak besar, ternak kecil dan ternak unggas. Jenis ternak besar yang cukup dominan di Kecamatan Pangalengan adalah sapi perah sebanyak 16.001 ekor, kerbau 20 ekor dan kuda sebanyak 8 ekor dan Sapi Potong 224 ekor. Sementara ternak kecil yang cukup dominan adalah domba sebanyak

7.011 ekor kemudian kambing sebanyak 428 ekor. Sedangkan jenis ternak unggas terbesar adalah ternak ayam, dimana pada tahun 2017 mencapai 39.701 ekor ( ayam kampung ) disusul itik sebanyak 2.809 ekor dan jenis ayam broiler 1.062.824 ekor yang di usahakan di Kecamatan Pangalengan.

Letaknya yang berada di daerah pegununganmenja dikn Kecamatan Pangalengan hanya memproduksi ikan hasil budidaya air tawar. Jumlah pembudidaya ikan dibedakan menurut keramba dan empang/kolam yang paling banyak di usahakan yaitu empang/kolam sebanyak kurang lebih 557 unit.

Tanaman perkebunan, yang diusahakan dan yang utama adalah teh dan kopi. Tanaman kopi yang diusahakan oleh masyarakat 912,10 Ha, pihak swasta 360,00 Ha. Tanaman Kopi meningkat di tahun sebelumnnya dan untuk tanaman Teh yang di kelola oleh masyarakat tercatat $328,97 \mathrm{Ha}$, pihak swasta / BUMN sebesar 5.682,02 Ha ini tanamnya ada di lahan adat, Swasta ada juga di lahan milik pemerintah /lahan kehutanan.

Desa Warnasari merupakan bagian dari Kecamatan Pangalengan Kabupaten Bandung Provinsi Jawa Barat. Desa Warnasari memiliki luas wilayah 2.354,119 Hektar, terletak pada ketinggian $\pm 1442 \mathrm{mdpl}$ dan memiliki suhu udara rata-rata $12^{\circ} \mathrm{C}-25^{\circ} \mathrm{C}$. Batas wilayah Desa Warnasari adalah sebelah utara Desa Pulosari, sebelah timur Desa Pulosari, sebelah selatan Desa Margaluyu dan sebelah barat Desa Pasir Jambu.

Desa Warnasari memiliki 17 Rukun 
Warga dan 17 kampung yaitu Baru Taraje, Ciawitali, Cibeunying, Cibunihayu, Cidurian, Cipangisikan, Citiis, Kapas, Kiaracondong, Munjul, Neglasari, Padahurip, Palayangan, Parabon, Pasir Ucing, Singkur, dan Wanasari. Lokasi TPK Warnasari berada didepan Jalan utama Desa Warnasari di RW 02 Kampung Wanasari berjarak \pm 300 meter ke sebelah barat dari kantor Desa Warnasari. Penempatan TPK Warnasari yang terletak di lokasi pusat desa mudah dijangkau oleh para peternak di daerah utara dan selatan serta memudahkan truk untuk mendistribusikan susu yang dikumpulkan peternak ke lokasi industri pengolahan susu.

Berdasarkan gambaran di atas, Desa Warnasari mempunyai potensi yang besar sebagai daerah penghasil produk pertanian yang dapat dikembangkan sebagai agroindustri dan agrowisata. Selain padi dan palawija, yang merupakan hasil pertanian secara umum, Desa Warnasari juga dikenal sebagai penghasil beberapa produk pertanian holtikultura. Dalam upaya pengembangan usaha tani di Desa Warnasari, pada dasarnya diperlukan keterlibatan para pelaku yang terdiri dari berbagai pihak seperti penghasil produk, pengolah, pedagang, distributor, importir dan eksportir. Pelaku-pelaku ini merupakan komponen atau subsistem yang membentuk sebuah sistem agribisnis. Sistem tersebut, di tahun-tahun mendatang diharapkan agar lebih berfungsi secara optimal demi mewujudkan tingkat kesejahteraan masyarakat. Oleh karena itu, pemerintah Desa Warnasari melalui program pembinaan dan pemberdayaan masyarakat akan selalu berupaya agar semua subsistem itu lebih siap dalam menjalankan perannya secara profesional.

Panorama alam yang ditawarkan oleh Situ Cileunca sangat indah serta hijaunya perkebunan teh Malabar dan tiga gunung yang mengelilingi yaitu gunung Malabar, gunung Windu, serta gunung Wayang menambah keindahan Situ Cileunca. ${ }^{1}$

Dalam konteks pariwisata, besarnya potensi wisata Situ Cileunca Desa Warnasari belum termanfaatkan secara baik. Salah satunya

${ }^{1}$ Hasil Observasi dan Wawancara Lapangan di Situ Cileunca pada tanggal 23 Juli 2017 adalah dimana belum dimanfaatkan kemampuan tour guide secara maksimal dikarenakan masyarakat ataupun yang menjadi tour guide di wilayah desa warnasari belum dapat mengoptimalkan kemampuan dari masyarakatnya yang sebagian besar adalah petani

Pengabdian pada masyarakat yang diajukan untuk dilaksanakan adalah pengembangan kemampuan Tour guide lokal di Desa Warnasari Kecamatan Pengalengan. Desa Warnasari adalah sebuah desa di kecamatan Pengalengan yang memiliki potensi keindahan alam yang sangat besar bahkan sebagian besar situs pariwisata yang ada Pengalengan terdapat di Warnasari. Desa Warnasari terletak 7 kilometer dari Kecamatan Pengalengan.

Potensi wisata alam Desa Warnasari memberikan dampak positif bagi masyarakat yang hidup disekitarnya. Dampak positif tersebut antara lain penyerapan tenaga kerja, yaitu para guide lokal yang semuanya merupakan masyarakat Desa Warnasari yang tentu saja dipilih oleh para pengurus, para penjual souvenir, para pegawai artshop, restoran dan kios-kios sekitar desa, sumber pemasukan bagi para pemilik tanah disepanjang jalan menuju objek wisata dan sekitarnya, dan perkembangan perdagangan hasil alam yang terdapat di desa Warnasari.

Dari berbagai manfaat wisata di atas maka kegiatan pariwisata disana harus dipertahankan dan dikembangkan. Salah satu upaya untuk meningkatkan pariwisata di Desa Warnasari adalah dengan memiliki penggerak pariwisata yang berkualitas. Maka dari itu di butuhkan tenaga Pemandu Wisata (Tour Guide) yang memiliki kemampuan khusus dalam berbahasa asing.

Khalayak strategis kegiatan ini adalah para 
guide lokal kawasan wisata Desa Warnasari. Para guide adalah yang berinteraksi langsung dengan wisatawan dan sumber informasi utama wisatawan ketika mengunjungi sebuah objek wisata. Oleh karena itu, mereka perlu memiliki kemampuan berbahasa asing khususnya Bahasa Inggris yang memadai. Namun, tidak demikian halnya dengan para guide lokal di desa Warnasari. Mereka tidak ada yang mempelajari teknik pemandu wisata secara formal, sehingga dipelukan pengetahuan manajemen pariwisata, selain pengembngn juga tetap adanya upaya untuk tetap menyeimbangkan lingkungan karena lingungan di desa warna sari saat ini masih terjaga baik tetap harus diepertahankan juga berupaya untuk mengembngkan potensi pariwisata di desa warnasari kegiatan ini untuk menmbah wawasan dan pengethuan juga menmbah kemmpuan dengan menggunakan bahasa Inggris sehingga kemampuan menjadi guide mereka bisa lebih memadai dikarenakan saat inii.karena bagaimanapun potens iwisata dengan dengan kekayaan keindahan yang dimilikinya tetap harus dijaga dan menjadi kekuatan dan daya tarik tersendiri begitu pula dengan potensi pariwisata pangalengn.

Sebagai upaya memanfaatkan potensi juga dengan harus adanya pemanduwisata yang mumpuni di wilayah warnasari sehingga perlu adanya kegiatan pengembangan kemmpuan tour Guide di Desa Warnasari.

Berdasarkan analisis situasi dan fakta di lapangan tersebut, maka dalam pengabdian kepada masyarakat ini dapat teridentifikasi masalah sebagai berikut. Para guide lokal kecamatan Warnasari belum memiliki kemampuan menjadi pemandu wisata yang memadai dalam menggunakan bahasa Inggris untuk menjalankan tugasnya menemani wisatawan asing

\section{B. METODE PENELITIAN}

Metode kegiatan dalam pengabdian pada masyarakat ini adalah pelatihan bahasa Inggris dalam bentuk pemberian materi tentang dasar- dasar bahasa Inggris untuk pemandu wisata bagi para guide lokal di Warnasari sebagai upaya meningkatkan kemampuan berkomunikasi dalam memandu wisatawan asing yang berkunjung kedesa Warnasari. Kegiatan ini direncanakan berkelanjutan dikarenakan daerah warnasari merupakan desa binaan FISIP UNPAS sehingga akan berkelanjutan selama 3 tahun

\section{HASIL PENELITIAN}

Khalayak strategis kegiatan ini adalah pemuda dan pemudi yang menjadi tourguide terdiri dari para pemuda dan tour guide yang bermata pencaharian sebagai pemandu di destinasi pariwita Kecamatan Warnasari. Nama peserta yang mengikuti pelatihan dapat dilihat pada tabel berikut :

\begin{tabular}{llll}
\hline No & Nama & No & Nama \\
\hline $\mathbf{1}$ & Rudi & 16 & Trisna Dwi Iman \\
2 & Denan & 17 & Yogi \\
3 & Rian & 18 & Mohamad Rizki \\
4 & Riki & 19 & Nuno \\
5 & Ujang & 20 & Nara \\
6 & Kurnia & 21 & M. habib \\
7 & Ian & 22 & Yusuf N \\
8 & Riki & 23 & A Rahmad \\
9 & Dian & 24 & Yudi Hermanto \\
10 & Cecep Gunawan & 25 & Kuswanto \\
11 & Tina & 26 & Fitrah \\
12 & Rizki & 27 & Cahya Permana \\
13 & Fausiah & 28 & Dasep \\
& & & Hermawan \\
14 & Deden & 29 & Wandi \\
& Suparman & & \\
15 & Fazar & 30 & Nusa \\
\hline
\end{tabular}

Kerangka dasar dari pemecahan masalah dalam pengabdian pada masyarakat ini adalah memberikan pengetahuan tentang pengembangan potensi pariwisata dengan cara memberikan pelatihandan pepengembangan potensi pariwisata yang berdaya saing tidak hanya ditingkat lokal nasional juga ketingkat global sehingga para tour guide diberikan pelatihan bahasa Ingris untuk tour guide di Kawasan Wisata Warnasari juga diberikan arahan untuk memanfaatkan juga menjaga kearifan local serta diberi pengetahuan untuk tetap menjaga keseimbangan lingkungan di derah Warnasari. 
Gambaran pelaksanaannya adalah sebagai berikut:

\section{a. Persiapan}

Tahapan persiapan adalah dengan acara menganalisis situasi di desa Warnasari untuk mengetahui kebutuhan dan pemecahan masalah dari yang dihadapi sehingga dapat diketahui aktifitas apa yang harus dilakukan atau menjadi Action Plan untuk pengabdian masyrakat meliputi mendata peserta yang akan mengikuti pelatihan dan kesiapan instruktur yang merupakan tim pengabdian, menyusun jadwal kegiatan, menyusun materi dan mempersiapkan tempat untuk kegiatan berlangsung.

\section{b. Pelaksanaan}

Ada beberapa langkah dalam pelaksanaan kegiatan pengabdian pada masyarakat.

Langkah-langkah tersebut yaitu:

1. Memberikan materi tentang dasar-dasar bahasa Inggris untuk pemandu wisata. Pemberian materi bahasa Inggris ini dilakukan oleh Bapak Drs. Alif Oktavian, M.H yang merupakan dosen Bahasa Inggris di Fisip Unpas.

2. Memberikan penjelasan konsep pemandu yag di lakukan oleh Ibu Tine Ratna Poerwantika, S.IP, M.Si

3. Materi manajemen Pariwisata oleh Bapak Drs.Kunkunrat M.Si dengan materi Peningkatan daya saing wisata

4. Materi Berkaitan dengan Bagaimana menjaga keseimbangan lingkugan diberkan oleh Ibu Dra. Rini Afriantari ., M.Si

5. Kegiatan ini tidak hanya pelatihan juga pendampingan selama 3 tahun berjalan dikarenanakn Desa Warnasari adalah Desa binaan FISIP UNPAS. Kegiatan ini dilaksanakan pada hari
Rabu 27 Februari dari pulul 10.00 sampai 15.00. Pemberi materi adalah tim pelaksana $\mathrm{P}_{3} \mathrm{M}$ ini sendiri yaitu, Drs. Alif Oktavian, MH, Drs. Tine Ratna Poerwantika, S.IP, M.Si, Drs. Kunkunrat, M.Si. Rini Afriantari Adapun dalam pelaksanaannya, kegiatan pelatihan di berikan beberapa materi serta modul pelatihan sebagai panduan dalam berlatih Bahasa Inggris. Dalam pelaksanaa kegiatan tersebut, para peserta sangat antusias dan beberapa diantaranya memberikan pertanyaan kepada pemateri.

Seluruh peserta yang hadir sebanyak 30 orang. Dan beberapa diantaranya sedang bekerja sebagai pemandu wisata ataupun bagi pemuda yang berkeingian menjadi pemandu wisatav Seperti dapat dilihat pada daftar absen (pada lampiran), 30 orang peserta tersebut mengikuti kegiatan pelatihan penuh dari jam

15.00 sampai sesi terakhir.

\section{KESIMPULAN}

Kegiatan ini merupakan kegiatan pelatihan serta pendampingan pagi para tour guide dengan mempersiapkan mereka agar dapat berdaya saing ditingkat local nasional bahkan global dengan memberikan pelatihan bahasa Inggris, manajemen , pengetahuan lingkungan untuk tour guide di kawasan wisata Warnasari. Kegiatan memiliki manfaat dan kegunaan terutama bagi para tour guide yang merupakan pemuda yang memiliki agresifitas tinggi terhadap pengetahuan yang diberikan juga pelatihan ini memberikan manfaat dalam upaya meningkatkan

kemampuan berkomunikasi tour guide dengan wisatawan asing, sehingga harapannya pelayanan terhadap tamu yang mengunjungi kawasan wisata Warnasari akan lebih baik. Motivasi mereka dalam mengikuti pelatihan juga tinggi, terlihat dari kehadiran mereka selama kegiatan pelatihan Perlunya pendampingan terutama 
melihat pelatihan yang telah dilaksakan bisa secara terus menerus dilakukan dan mengetahui progress dari pelatiahan tersebut.

\section{E. REFERENSI}

Aziz, H Moh. Ali. 2005. Pendekatan

Sosio Kultural Dalam Pemberdayaan

Masyarakat. Dalam Rr. Suhartini, Dkk (eds), Model-model Pemberdayaan Masyarakat, Yogyakarta, Pstaka Pesantren (Kelompok Penerbit LKIS)

Bronson, J. 2001. 7 Characteristics of a Good Tour Guide. Tersedia pada:

http://www.parksinperil.org/files/d_1_1_o7_c haracteristics/. Diakses pada 22 maret 20019 dpdhisulut. 2008.Apa itu pramuwisata?.Tersedia pada: http://www.dpdhpisulut.wordpress.com/2008 /11/apa-itu-pramuwisata/. Diakses pada 26 Maret 2016 